\title{
Higher levels of trait impulsiveness and a less effective response inhibition are linked to more intense cue-elicited craving for alcohol in alcohol- dependent patients
}

Citation for published version (APA):

Papachristou, H., Nederkoorn, C., Havermans, R., Bongers, P., Beunen, S., \& Jansen, A. (2013). Higher levels of trait impulsiveness and a less effective response inhibition are linked to more intense cue-elicited craving for alcohol in alcohol-dependent patients. Psychopharmacology, 228(4), 641-649.

https://doi.org/10.1007/s00213-013-3063-3

Document status and date:

Published: 01/01/2013

DOI:

10.1007/s00213-013-3063-3

Document Version:

Publisher's PDF, also known as Version of record

Document license:

Taverne

Please check the document version of this publication:

- A submitted manuscript is the version of the article upon submission and before peer-review. There can be important differences between the submitted version and the official published version of record. People interested in the research are advised to contact the author for the final version of the publication, or visit the DOI to the publisher's website.

- The final author version and the galley proof are versions of the publication after peer review.

- The final published version features the final layout of the paper including the volume, issue and page numbers.

Link to publication

\footnotetext{
General rights rights.

- You may freely distribute the URL identifying the publication in the public portal. please follow below link for the End User Agreement:

www.umlib.nl/taverne-license

Take down policy

If you believe that this document breaches copyright please contact us at:

repository@maastrichtuniversity.nl

providing details and we will investigate your claim.
}

Copyright and moral rights for the publications made accessible in the public portal are retained by the authors and/or other copyright owners and it is a condition of accessing publications that users recognise and abide by the legal requirements associated with these

- Users may download and print one copy of any publication from the public portal for the purpose of private study or research.

- You may not further distribute the material or use it for any profit-making activity or commercial gain

If the publication is distributed under the terms of Article 25fa of the Dutch Copyright Act, indicated by the "Taverne" license above, 


\title{
Higher levels of trait impulsiveness and a less effective response inhibition are linked to more intense cue-elicited craving for alcohol in alcohol-dependent patients
}

\author{
Harilaos Papachristou • Chantal Nederkoorn • \\ Remco Havermans • Peggy Bongers • Shalana Beunen • \\ Anita Jansen
}

Received: 31 October 2012 / Accepted: 6 March 2013 /Published online: 19 March 2013

(C) Springer-Verlag Berlin Heidelberg 2013

\begin{abstract}
Rationale Cue-elicited craving is a well-researched phenomenon in alcohol literature. However, not all alcoholdependent people display the same reactivity to alcohol cues. Personality factors such as multiple impulsivity traits may be responsible for individual differences in cue reactivity by modulating its intensity. Nevertheless, there has been a scarcity of empirical studies testing this assumption in alcohol literature.

Objectives The aim of the present study was to investigate the effects of response inhibition and trait impulsiveness on cue-elicited craving for alcohol in alcohol-dependent drinkers. Methods Participants $(n=41)$ were inpatients of the private clinic U-Center, Netherlands. Alcohol exposure took place in a real bar-restaurant close to the premises of the clinic, and participants were exposed to real alcohol cues. Response inhibition was assessed with the stop-signal task and trait impulsiveness with the Barratt impulsivity scale version 11 .

Results The cue exposure was successful as alcoholdependent patients experienced higher craving for alcohol when exposed to alcohol rather than to neutral cues. Additionally, both response inhibition and trait impulsiveness predicted cue-elicited craving for alcohol. Trait impulsiveness predicted both the absolute craving in the barrestaurant and the increase in cue-elicited craving during the whole alcohol cue exposure, while response inhibition predicted only the former.
\end{abstract}

H. Papachristou $(\bowtie) \cdot$ C. Nederkoorn $\cdot$ R. Havermans $\cdot$

P. Bongers $\cdot$ S. Beunen $\cdot$ A. Jansen

Faculty of Psychology and Neuroscience, Maastricht University, P.O. Box 616, 6200 MD Maastricht, the Netherlands

e-mail: h.papachristou@maastrichtuniversity.nl

H. Papachristou

U-Center, Epen, the Netherlands
Conclusions The results clearly implicate both trait impulsiveness and response inhibition in the modulation of cueelicited craving in alcohol dependence. Theoretical and methodological issues in the findings and their clinical implications in alcohol treatment and relapse are discussed.

Keywords Alcohol dependence $\cdot$ Cue reactivity $\cdot$ Craving · Alcohol cue exposure $\cdot$ Impulsivity $\cdot$ Response inhibition . Trait impulsiveness

\section{Introduction}

In alcohol literature, cue reactivity refers to the finding that when heavy drinkers and alcohol-dependent individuals are exposed to alcohol-related cues, their craving for alcohol increases and their physiology (e.g., salivation, skin conductance response, heart rate) changes (Carter and Tiffany 1999; Drummond 2000). Nevertheless, although cue reactivity is a well-researched phenomenon, there is still controversy about the factors involved in it. After all, not every alcohol-dependent individual shows the same reactivity to alcohol cues, which implies that there are other factors that moderate its intensity. Impulsivity is a possible candidate here (Papachristou et al. 2012a).

In general, impulsivity is defined as the tendency to respond fast to environmental and internal stimuli without planning or consideration of the consequences of one's behavior (Dawe and Loxton 2004). However, it appears that impulsivity is a multidimensional construct that consists of heterogeneous traits that reflect distinct etiologies and psychobiological mechanisms and are assessed via different instruments and methods (Dawe and Loxton 2004; de Wit 2008; Whiteside and Lynam 2001, 2003). 
Typically, impulsivity is measured via self-report questionnaires and behavioral tasks (Verdejo-Garcia et al. 2008). There is evidence that these two types of measurement correlate weakly with each other and explain unique variance in problem drinking (Christiansen et al. 2012). These findings give further support to the notion that impulsivity is an umbrella construct consisting of unrelated concepts (Enticott et al. 2006; Dick et al. 2010). It also seems that impulsivity is conceptualized differently in each type of measure. In self-report measures, it is regarded as a dispositional characteristic and scores represent relatively stable individual differences in perceiving and reacting to the world (Dick et al. 2010; de Wit 2008; Verdejo-Garcia et al. 2008). On the other hand, behavioral measures assess specific cognitive processes and are more sensitive to momentto-moment fluctuations in impulsivity levels within an individual (Christiansen et al. 2012; Verdejo-Garcia et al. 2008). Although self-report measures appear to have a better ecological validity than behavioral measures, the former are more easily influenced by social desirability bias than the latter (Enticott et al. 2006; Verdejo-Garcia et al. 2008).

Both types of measurement have been used to assess impulsivity in alcohol-dependent and heavy drinkers (Christiansen et al. 2012; Verdejo-Garcia et al. 2008). Regarding self-report measures, the Barratt impulsivity scale version 11 is commonly used in alcohol studies as a measure of trait impulsiveness (BIS-11; Patton et al. 1995; Christiansen et al. 2012). For example, Von Diemen et al. (2008) have found that trait impulsiveness is strongly associated with alcohol and substance use disorders. Additionally, Dom et al. (2006) reported that early-onset alcohol-dependent patients have higher BIS-11 scores than late-onset patients.

Regarding behavioral measures, behavioral inhibition tasks are frequently used in alcohol and substance abuse studies (de Wit 2008). These tasks assess response inhibition or the ability to stop a well-learned motor response upon the appearance of new information. The stopping (in) ability can be assessed either before the initiation of the response (action restraint measured with the go/no-go task) or after the initiation of the response (action cancellation measured with the stop-signal task) (Eagle et al. 2008). Nigg et al. (2006) reported that impaired response inhibition, measured with the stop-signal task (SST), predicts alcoholrelated problems in adolescents with a vulnerability to alcohol and substance abuse disorders. In the same vein, Nederkoorn et al. (2009) have demonstrated that heavy drinking is associated with less effective response inhibition (SST) in women but not in men. Finally, Rubio et al. (2008) have shown that both trait impulsiveness and response inhibition (SST) are predictors of alcohol dependence in heavy drinkers in a 4-year follow-up study.

Cue elicited craving is a central characteristic of any substance dependence, and the relationship between impulsivity traits and substance dependence might reflect individual differences in experienced levels of such cue reactivity. The association of either trait impulsiveness or response inhibition with cue-elicited craving for alcohol or other drugs is not well-researched in the literature, but there are two studies that show a relationship between trait impulsiveness and subjective and physiological cue reactivity in nicotine-dependent smokers (Doran et al. 2007, 2008). Further, there is one study with social drinkers that examined the role of both impulsivity dimensions on cue-elicited craving for alcohol (Papachristou et al. 2012a). It was found that response inhibition but not trait impulsiveness is associated with higher cue-elicited craving for alcohol in heavy social drinkers. However, there is no study on the effects of either trait impulsiveness or response inhibition on cueelicited craving for alcohol in alcohol-dependent people. The scarcity of research on this topic is surprising, given the view that cue-elicited craving is an index of approach behavior towards alcohol and drugs of abuse (Anton 1999; Carter and Tiffany 1999). Consequently, a less effective response inhibition or higher trait impulsiveness could weaken the inhibition of approach behavior to such cues and contribute to relapse (Doran et al. 2007; Dawe et al. 2004). Clearly, there is a need for more studies in the field that could shed light on this complex relationship.

The aim of the present study was to examine whether response inhibition and trait impulsiveness have an effect on cue-elicited craving for alcohol in alcohol-dependent people. The participants of the present study were inpatients of the private clinic U-Center, Netherlands. Alcohol exposure took place in a real bar-restaurant nearby the private clinic; hence, participants were exposed to real alcohol cues in a real alcohol-related setting. It was hypothesized that (1) alcohol-dependent people experience higher craving for alcohol when exposed to alcohol than to water cues, (2) a higher trait impulsiveness score is associated with higher cue-elicited craving for alcohol in alcohol-dependent people, and (3) a less effective response inhibition is associated with higher cue-elicited craving for alcohol in alcoholdependent people.

\section{Methods}

\section{Participants}

Forty-one patients ( 22 men and 19 women; mean age $=51$. $15, \mathrm{SD}=10.9)$ undergoing a six-week inpatient alcohol treatment program at the private clinic, U-Center, Netherlands, were recruited for the present study. All patients had been diagnosed by the staff psychiatrists with a DSM-IV diagnosis of alcohol dependence. Thirty-one patients (75.61\%) had a multiple diagnosis (another Axis-I disorder or a 
combination of Axis-I and Axis-II disorders), and ten patients $(24.39 \%)$ had been diagnosed only with alcohol dependence. None of the patients had been diagnosed with either antisocial or borderline personality disorder or with attention deficit hyperactivity disorder. Four patients $(9$. $76 \%$ ) had a second diagnosis of cannabis dependence, two patients $(4.88 \%)$ of cocaine dependence, and twentytwo patients $(53.66 \%)$ smoked more than 15 cigarettes per day.

Inclusion criterion was a diagnosis of alcohol dependence. Exclusion criteria were a history of psychosis or bipolar disorder, organic serious brain impairment, and any prescribed psychoactive medication that could interfere with craving and psychomotor performance. Participants were benzodiazepine-free at the time of testing. All participants were tested after detoxification and within the first three weeks of their treatment in the U-Center.

\section{Measures}

Trait Impulsiveness The Dutch version of the BIS-11 (Patton et al. 1995) was used to assess trait impulsiveness. It consists of 30 items and is divided into three factors: motor (acting without thinking), attentional (not focusing on the task at hand and cognitive instability), and nonplanning impulsiveness (lack of self-control and difficulty orientating to the future).

Participants had to report on a 4-point scale; the extent to which a series of statements applies to them from "Rarely/Never" to "Always/Almost Always". Scores vary from 30 (low trait impulsiveness) to 120 (high trait impulsiveness). Previous research with clinical and nonclinical populations has demonstrated the reliability of the questionnaire with Cronbach's alpha coefficient ranging from .79 to . 83 (Patton et al. 1995). In the current study, the Cronbach's alpha coefficient was .78.

Response inhibition The SST was used to assess response inhibition (Logan et al. 1997). It consists of two parallel trials, a go and a stop paradigm. The task begins with a $500 \mathrm{~ms}$ fixation point in the center of a computer screen. Next, a go trial follows. In each go trial, a picture of a square pattern is displayed either on the left or the right of the center of the screen for 1,500 ms. Participants are instructed to respond as fast as possible by pressing the right "shift" button with the right hand when the square pattern is depicted on the right part of the screen, and the left "shift" button with the left hand when the square pattern is portrayed on the left part of the screen. Between trials, the screen becomes blank for $1,000 \mathrm{~ms}$. However, in $25 \%$ of the go trials, an auditory stop signal is emitted through headphones after the go signal, signaling that the participants must inhibit their response. The stop signal is a $1,000 \mathrm{~Hz}$ tone lasting $100 \mathrm{~ms}$. In the beginning, the auditory stop signal occurs $250 \mathrm{~ms}$ after the go signal (stop-signal delay $=250 \mathrm{~ms}$ ), but throughout the task, the duration of the interval changes depending on the participant's performance. After a failure to successfully inhibit the response, the next stop signal is presented $50 \mathrm{~ms}$ earlier, thus, making the task easier. Conversely, when the participant inhibits the response successfully, the next stop signal is heard $50 \mathrm{~ms}$ later, thereby making the task more difficult. These adjustments allow participants to effectively withhold their responses roughly at $50 \%$ of the stop trials. The average percentage of correct responses in the present task was $46 \%(n=32)$.

In the present task, there are three practice blocks, consisting of 6,12 , and 24 trials, respectively. The practice blocks are followed by four test blocks of 64 trials each. Between blocks, participants are permitted to have a short break. There are three dependent variables in the task: mean GO reaction time (RT), mean stop-signal delay (SSD), and stop-signal reaction time (SSRT). The SSRT is the difference between the mean Go RT and the mean SSD measured in milliseconds (ms). A higher SSRT indicates that a participant is slower to inhibit a prepotent response; hence, it is an indicator of impaired response inhibition.

\section{Craving}

Craving was assessed with two $100-\mathrm{mm}$ visual analogue scales (VAS) ranging from 0 (not at all) to 100 (very much). Participants were asked to indicate (1) their desire to consume alcohol: "How much do you feel like drinking alcohol right now?" and (b) their urge to drink alcohol: "How strong is your urge to drink alcohol right now?" In general, it has been shown that VASs are valid and reliable indicators of craving for alcohol (Kozlowski et al. 1996). In the current study, the Cronbach's alpha and the correlation coefficient $r$ between the two items at each level of cue exposure was acceptable: (1) water baseline: Cronbach's $\alpha=.65 ; \mathrm{r}=.56, p<.001$, (2) water exposure: Cronbach's $\alpha=.74 ; \mathrm{r}=.71, p<.001$, (3) alcohol baseline: Cronbach's $\alpha=.81 ; \mathrm{r}=.75, p<.001$, (4) alcohol exposure: Cronbach's $\alpha=.87 ; \mathrm{r}=87, p<.001$.

Two types of craving scores were calculated in the present study. The first type is the change in craving during the whole cue-exposure procedure after adjusting for baseline levels and exposure to neutral cues. The second type is the absolute craving score during the alcohol cue-exposure in the bar-restaurant. Both measures could be important in the daily life of alcohol-dependent people because both of them could be related to relapse. However, the latter type of craving may not be necessarily cue-specific and may also include nonassociative components, such as withdrawal craving (Sayette et al. 2000; Robbins and Ehrman 1992). As Sayette et al. (2000) argue, both measures could be meaningful in cue reactivity studies, and the distinction 
between them may result in different interpretations of the data. As very little research has been conducted on the relationship between impulsivity and craving in alcoholdependent people, it was assumed that both craving scores are of interest and should be included in the present study in order to investigate in more depth the nature of this interaction.

\section{Procedure}

Ethical approval was obtained from both the Ethics Committee of the Psychology Faculty of Maastricht University and the Ethics Committee of the U-Center. All the participants had to fill in an informed consent form in which it was explained that they would be exposed to alcohol-related cues in the nearby bar-restaurant. However, while being at the U-Center, none of the participants was informed that the goal of the study was to assess the relationship between trait impulsiveness/response inhibition and cue-elicited craving for alcohol. Participants were debriefed via mail/email after having completed their treatment program at the U-Center. All testing took place in the clinic (U-Center) and in a nearby bar-restaurant between 1:30 and 6:00 p.m. Participants took part in two individual sessions planned in the same week and always on the same days (Mondays and Wednesdays).

Before the first session, the participants had been contacted by the staff of the clinic and had been informed broadly about the study. Only those participants who showed interest in the study were invited to the first session. During the first session, the informed consent form was first administered to the patients. In the form, they were told that the study investigates reactions to alcohol cues and that they would be exposed to alcohol-related cues in a real barrestaurant. Only after the patient agreed and signed the consent form, they were allowed to participate in the study. After signing the form, participants were presented with a brief demographic questionnaire and then performed the SST and filled out the BIS-11. The order of the task and the BIS-11 was counterbalanced between participants.

Having finished with the tasks/questionnaires, participants were exposed to water cues in the clinic. They were offered a glass filled with tap water and the experimenter instructed them to focus on the water, imagine how it tastes, pick up and hold the glass, and sniff the water in the glass. She also invited the patient to imagine a situation in which drinking water would be pleasant. During the exposure, the patients had to bring the glass close to their nose and mouth, close their eyes, and imagine that they take a sip and that the water is all over their mouth and throat. The experimenter herself modeled the instructions thus ensuring that the patient knew exactly what to do and did not feel overly selfconscious during the exposure. From time to time, the experimenter had a small chat with the patient about the type of water they drink (e.g., carbonated water), and in general about the issue of drinking water. The patient was free to express their thoughts and feelings about the topic. At other times, the patients were left alone in their thoughts while holding the glass of water and after being instructed to concentrate on its transparent texture/color. These instructions were repeated every $5 \mathrm{~min}$. After the water exposure, each patient was asked to provide information about the place, time, feelings, and people surrounding a typical alcohol drinking episode. The experimenter used this information during the alcohol exposure along with exposure to real alcohol cues.

Two days after the water exposure, the alcohol exposure session took place. Once more, the experimenter reminded the patient that the exposure would occur in a nearby barrestaurant with real alcohol cues and that the patient was free to quit the study if they felt uncomfortable. It was also stated explicitly that drinking during the alcohol exposure was not allowed and that in case that any drinking occurred, the exposure would stop immediately. Then, the experimenter took the patient to the bar-restaurant and they sat together at a table. When the patient felt ready, both the experimenter and the patient ordered their own favorite alcoholic beverage, respectively. Following this, the experimenter gave the same instructions to the patient as she had done in the water exposure and as before she modeled the instructions. After the alcohol cue exposure, the patient was led back to the clinic by the experimenter and was explicitly told to contact the staff of the clinic in case they felt dysphoria or had any other distressing symptoms.

The two sessions were not counterbalanced in order; thus, water exposure was always first, and alcohol exposure was always second in order. It was thought that exposure to real alcohol cues in a real alcohol-related setting would be a stressful experience for the patients, and asking them to start the study with the alcohol exposure might have resulted in high stress levels.

Baseline craving ratings were taken before the water exposure and also before the alcohol exposure while the patient was still in the clinic. During each cue exposure condition, craving was measured every $5 \mathrm{~min}$. If after $15 \mathrm{~min}$ of cue exposure and craving levels did not increase more or had returned back to baseline levels, the cue exposure was stopped. If craving did increase during cue exposure, the experimenter continued the exposure till craving returned back to baseline levels, or till the maximum time of 60 min was reached.

Statistical analysis

Inspection of the SSRTs showed that nine participants (almost) never inhibited their responses during the performance of the SST. Due to their spurious performance in the 
task, these participants were excluded from any response inhibition analysis, though they were included in the analysis of trait impulsiveness and cue exposure. Similar to our earlier study (Papachristou et al. 2012a), there was no statistically significant relationship between trait impulsiveness and response inhibition, ( $\mathrm{r}=-.01 ; \mathrm{ns}, n=32)$.

Firstly, a 2-way cue type (water vs. alcohol) $\times$ time (baseline vs. exposure) repeated-measures ANCOVA was performed to assess the effects of cue exposure on craving. Age was centered and entered as a covariate in the analysis because it correlated negatively with cue-elicited craving for alcohol in the alcohol condition $(\mathrm{r}=-.50, p=.001)$. The peak intensity of alcohol craving at baselines and during each cue exposure was the dependent variable and was calculated by averaging the maximum craving scores across the two visual analogue scales for each participant. Effect sizes were reported as eta squared $\left(\eta^{2}\right)$. Greenhouse-Geisser correction was used when Mauchly's test of sphericity was significant.

Based on the peak craving scores, a difference craving score was computed for each cue exposure condition (water: exposure-baseline; alcohol: exposure-baseline). Then, an overall difference craving score was estimated by subtracting the aforementioned differences from each other (alcohol difference-water difference). The latter difference score, a measure of the increase in craving for alcohol during exposure to alcohol cues, was the criterion variable in two hierarchical linear regression models with age and trait impulsiveness (1st model) and age and response inhibition (2nd model) as their predictors, respectively. Further analysis with the BIS-11 subscales was also performed. Age was entered as a predictor in the models because it correlated negatively both with craving (Trait impulsiveness model: $\mathrm{r}=-.41, p<.01$; response inhibition model: $\mathrm{r}=-.37, p<.05$ ) and with the overall score in trait impulsiveness $(\mathrm{r}=-.31$, $p<.05$ ) (but not with response inhibition, $\mathrm{r}=.28$, ns). No correlations with gender and impulsivity or craving were significant. In addition, the same two regression models were used to predict the absolute maximum craving for alcohol during the exposure in the bar-restaurant (craving at water/alcohol baselines and during water exposure not subtracted) in order to obtain a more clinically relevant measure of peak cue-elicited craving for alcohol.

\section{Results}

The effects of cue exposure on peak cue-elicited alcohol craving

There was a statistically significant 2 -way interaction between cue type and time on peak craving, $F(1,39)=28.56$, $\eta^{2}=.38, p<.001$. Further analysis demonstrated that during the water condition, there was a slight but nonsignificant decrease in alcohol craving from baseline to exposure, (mean difference $\left.=-.59, \mathrm{~F}(1,39)=0.25, \eta^{2}=.00, \mathrm{~ns}\right)$. On the other hand, during the alcohol condition, there was a significant increase in peak craving from baseline to exposure, $\left(\right.$ mean difference $=10.01, \mathrm{~F}(1,39)=26.86, \eta^{2}=.34$, $p<.001$ ) (Fig. 1). Additionally, there was no statistically significant main effect of cue type on peak craving, $\mathrm{F}$ $(1,39)=3.42, \eta^{2}=.08$, ns (Fig. 1). Finally, a statistically significant main effect of time on peak craving was found, $\mathrm{F}(1,39)=14.16, \eta^{2}=.22, p<.001$. Regardless of cue type, peak craving for alcohol was higher after cue exposure $(\mathrm{M}=12.84, \mathrm{SE}=2.41)$ than at baseline $(\mathrm{M}=8.12, \mathrm{SE}=1.84)$ (Fig. 1).

The results also showed a significant main effect of age on peak craving, $\mathrm{F}(1,39)=10.19, \eta^{2}=.21, p<.01$ and a significant 3-way interaction between cue type, time, and age on peak craving, $\mathrm{F}(1,39)=7.91, \eta^{2}=.10, p<.01$. To further analyze the effect of age on the 2-way interaction, a
Fig. 1 Peak intensity of craving for alcohol during water and alcohol baselines and cue exposure

\section{The effects of cue exposure on alcohol craving}

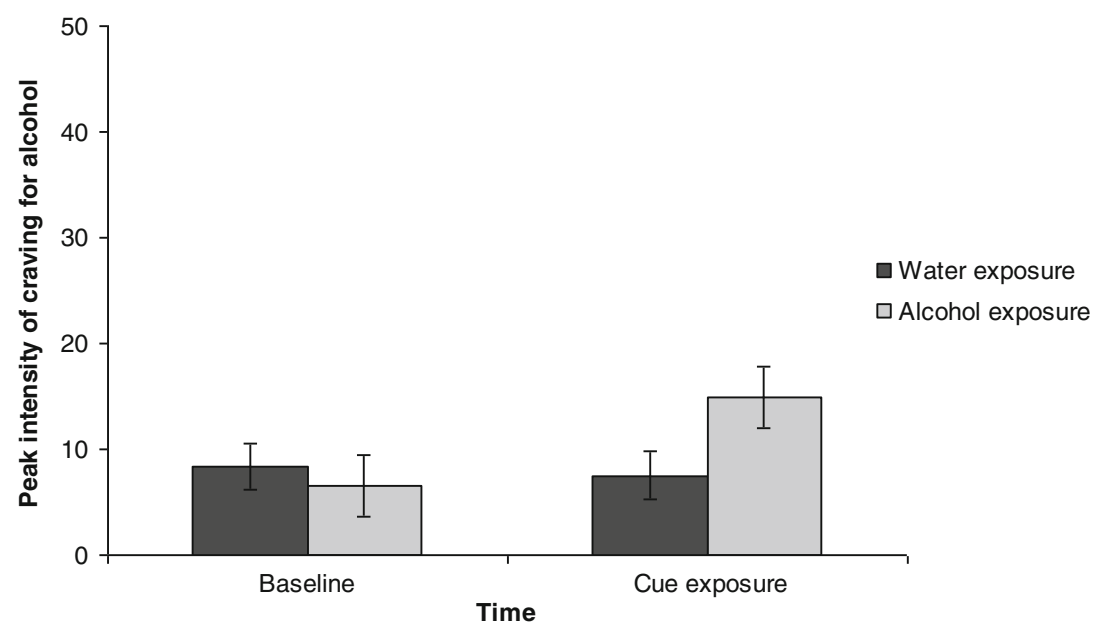


median split (Median=53 years) was performed on age, and the participants in the present study were divided into two age groups: "younger" and "older". The results showed that the 2-way interaction cue type $\times$ the time on peak craving was statistically significant for both age groups (Younger: $\mathrm{F}$ $(1,19)=20.93, \eta^{2}=.52, p<.001$; Older: $\mathrm{F}(1,20)=7.63$, $\eta^{2}=.28, p<.05$ ). Further analysis indicated that the maximum intensity of cue-elicited craving for alcohol did not change significantly during the water condition (exposurebaseline) in either age group, (Younger: $F(1,19)=0.18$, $\eta^{2}=.01$, ns; Older: $F(1,20)=2.91, \eta^{2}=.13$, ns). During the alcohol condition, however, both groups experienced higher peak craving after cue exposure compared to baseline, but the increase in peak intensity of craving in younger participants was higher than in older participants, (Younger: mean difference $=17.16, \mathrm{SE}=3.71, \mathrm{~F}(1,19)=21.46, \eta^{2}=.53$, $p<.001$; Older: mean difference $=3.19, \mathrm{SE}=1.34, \mathrm{~F}(1,20)=5$. $70, \eta^{2}=.22, p<.05$ ).

Finally, after inspection of the data, there were 12 participants who did not experience an increase in craving during the whole cue exposure. This number corresponds to approximately one fourth of the participants in the present study and is in agreement with the results of previous studies in the literature (Litt et al. 2000).

Trait impulsiveness and increase in craving for alcohol during alcohol cue exposure

Hierarchical linear regression was conducted to evaluate how well trait impulsiveness predicts the increase in craving for alcohol during alcohol cue exposure, after controlling for the effects of age on craving. The increase in maximum levels of cue-elicited craving for alcohol, after subtracting craving at baselines and during water exposure (see statistical analysis), was the criterion variable, and trait impulsiveness and age were the predictors. Age was entered at step 1 of the analysis, while trait impulsiveness was entered at step 2 . At step 1 , age explained $17 \%$ of the variance of cue-elicited alcohol

Table 1 Linear regression analyses, with age, trait impulsiveness (total score and subscales), and response inhibition as predictors of the increase in cue-elicited craving (craving at baselines/water craving, $\mathrm{F}(1,39)=7.91, p=.008$. After entry of the BIS-11 at step 2 , the total variance explained by the model as a whole was $26.8 \%, \mathrm{~F}(2,38)=6.95, p=.003$. After controlling for age, trait impulsiveness explained approximately an additional $10 \%$ of the variance in cue-elicited craving for alcohol, $\mathrm{F}$ change $(1,38)=5.15, p=.029$ (Table 1). Further analysis showed that after controlling for age, the attentional impulsiveness and the nonplanning impulsiveness subscales of trait impulsiveness do not predict the increase in cue-elicited craving for alcohol, (attentional impulsiveness: $\mathrm{F}(1,38)=1.26$, ns, $\Delta \mathrm{R}^{2}=.027$; nonplanning impulsiveness: $\mathrm{F}(1,38)=2.4$, ns, $\left.\Delta \mathrm{R}^{2}=.049\right)$. However, the motor impulsiveness subscale successfully predicts the increase in cue-elicited craving for alcohol, $\mathrm{F}(1,38)=6.14$, $p=.018, \Delta \mathrm{R}^{2}=.12$ (Table 1). The hierarchical linear regression results suggest that alcohol-dependent patients with higher levels of trait impulsiveness tend to experience a higher increase in cue-elicited craving for alcohol than alcohol-dependent patients with lower levels of trait impulsiveness.

Response inhibition and increase in craving for alcohol during alcohol cue exposure

Hierarchical linear regression was performed to assess whether response inhibition predicts the increase in craving for alcohol during alcohol cue exposure, after controlling for the influence of age. The increase in maximum levels of cue-elicited craving for alcohol, after subtracting craving at baselines and during water exposure (see statistical analysis), was the criterion variable, and SSRT and age were the predictor variables in the model. Age was entered at step 1, explaining $16.1 \%$ of the variance of cue-elicited alcohol craving, $\mathrm{F}(1,30)=5.76, p=.023$. After entry of the SSRT at step 2 , the model was not significant any more, $F(2,29)=$ 2.89 , ns (Table 1). Based on these results, response inhibition levels appear to have little predictive power over the increase in cue-elicited craving for alcohol in alcohol-dependent patients. exposure subtracted) and absolute craving (craving at baselines/water exposure not subtracted) during alcohol cue exposure in the barrestaurant

\begin{tabular}{|c|c|c|c|c|c|c|c|c|}
\hline \multirow[b]{2}{*}{ Predictors } & \multicolumn{4}{|c|}{ Increase in craving to alcohol cues } & \multicolumn{4}{|c|}{ Absolute craving to alcohol cues } \\
\hline & $\mathrm{B}$ & SE B & $\beta$ & $\Delta \mathrm{R}^{2}$ & $\mathrm{~B}$ & SE B & $\beta$ & $\Delta \mathrm{R}^{2}$ \\
\hline Trait impulsiveness (BIS-11) & 0.48 & 0.21 & $.33^{*}$ & .10 & 1.10 & 0.33 & $.43 * *$ & .17 \\
\hline Motor impulsiveness (BIS-11) & 1.23 & 0.5 & $.36^{*}$ & .12 & 2.4 & 0.8 & $.4 * *$ & .14 \\
\hline Attentional impulsiveness (BIS-11) & 0.61 & 0.54 & .17 & .03 & 2.21 & 0.84 & $.35^{*}$ & .11 \\
\hline Nonplanning impulsiveness (BIS-11) & 0.72 & 0.46 & .23 & .05 & 1.37 & 0.76 & .24 & .06 \\
\hline Response inhibition (SSRT) & 0.02 & 0.04 & .08 & .005 & 0.16 & 0.06 & $.39 *$ & .14 \\
\hline
\end{tabular}

$* p<05 ; * * p<.01$ 
Trait impulsiveness and absolute craving for alcohol during alcohol cue exposure

Hierarchical linear regression was performed to examine whether trait impulsiveness predicts craving during the alcohol cue exposure, after controlling for the effects of age. The maximum absolute craving score during exposure to alcohol cues (exposure that took place in the bar-restaurant) was the criterion variable, and trait impulsiveness and age were the predictors. Age was entered at step 1 of the analysis, while trait impulsiveness was entered at step 2. At step 1, age accounted for 25 . $4 \%$ of the variance of cue-elicited alcohol craving, $\mathrm{F}$ $(1,39)=13.30, p=.001$. After entry of the BIS-11 scores at step 2 , the total variance explained by the model as a whole was $42.4 \%, F(2,38)=13.96, p<.001$. After controlling for age, trait impulsiveness explained approximately an additional $16.9 \%$ of the variance in peak craving for alcohol during exposure to alcohol cues, $\mathrm{F}$ change $(1,38)=11.16, p=.002$ (Table 1). Further analysis indicated that both the attentional and motor impulsiveness subscales but not the nonplanning impulsiveness subscale predict absolute craving, (attentional impulsiveness: $\mathrm{F}(1,38)=6.88, p=.012, \Delta \mathrm{R}^{2}=.11$; Motor Impulsiveness: $\mathrm{F}(1,38)=9.05, p=.005, \Delta \mathrm{R}^{2}=.14$; nonplanning impulsiveness: $\mathrm{F}(1,38)=3.21$, ns, $\left.\Delta \mathrm{R}^{2}=.06\right)$ (Table 1). These findings indicate that alcohol-dependent patients with higher levels of trait impulsiveness tend to experience a higher peak craving when exposed to alcohol cues than alcohol-dependent patients with lower levels of trait impulsiveness.

Response inhibition and absolute craving for alcohol during alcohol cue exposure

Hierarchical linear regression was performed to assess whether response inhibition predicts craving during exposure to alcohol cues, after controlling for the influence of age. The maximum absolute craving score during exposure to alcohol cues (exposure that took place in the bar-restaurant) was the criterion variable, and SSRTs and age were the predictor variables in the model. Age was entered at step1 explaining $30.1 \%$ of the variance of craving during exposure to alcohol cues, $\mathrm{F}(1,30)=12.94, p=$. 001. After entry of the SSRTs at step 2, the model was still significant, F $(2,29)=11.36, p<.001$. After controlling for age, response inhibition levels accounted for 13 . $8 \%$ of the variance in craving during the alcohol cue exposure, $\mathrm{F}$ change $(1,29)=7.13, p=.012$ (Table 1). It seems that alcohol-dependent patients with less effective response inhibition tend to experience higher peak craving when exposed to alcohol cues than patients with more effective response inhibition.

\section{Discussion}

In the present study, it was hypothesized that (1) alcoholdependent patients experience more intense craving for alcohol when exposed to alcohol rather than to water cues, (2) higher levels of trait impulsiveness, and (3) a less effective response inhibition are linked to more intense cue-elicited craving for alcohol in alcohol-dependent patients.

First of all, alcohol-dependent patients experience a higher increase in alcohol craving when exposed to alcohol as compared to neutral cues. This finding confirms the first hypothesis of the present study. Knowing that cue-elicited craving for alcohol is usually weaker than cue-elicited craving for other substances of abuse, we tried to apply some fundamental guidelines in order to obtain a reliable effect (Tiffany et al. 2000; Carter and Tiffany 1999; Rohsenow and Niaura 1999). Therefore, great efforts were made to develop a strong cue exposure with personally relevant stimuli in a real alcohol-related environment and to expose the patients to a combination of cues for as long as possible, while always bearing in mind that this experience was stressful for them. Although limited, the increase in cueelicited craving for alcohol is significant and of a moderate effect size. Our finding is in line with well-established findings in the alcohol cue reactivity literature, and once more it demonstrates that alcohol craving shows cue specificity (Tiffany et al. 2000; Carter and Tiffany 1999; Havermans et al. 2007). Most important, a successful cue exposure was the cornerstone of our study because a consistent cue-elicited craving response is necessary in order to identify the factors that are involved in this phenomenon (Carter and Tiffany 1999).

The results also confirm the second and third hypotheses of our study. It was found that trait impulsiveness predicted both the absolute craving in the bar-restaurant and the increase in cue-elicited craving during the whole alcohol cue exposure, while response inhibition predicted successfully only the former. The former type of craving is a threat for relapse in real life, and it may be even more clinically relevant than the increase in cue-elicited craving in alcohol dependence. Future research should investigate whether the interaction of cue-elicited craving with impulsivity traits predicts relapse in alcohol dependence. If empirical evidence supports this assumption, then alcohol treatment and prevention programs might benefit from impulsivity interventions in combination with cue exposure with response prevention programs.

Our findings are in line with Doran et al.'s (2007) findings, who also reported that a stronger increase in cue-elicited craving for tobacco is associated with higher scores in trait impulsiveness. Furthermore, our results are partly in agreement with Papachristou et al.'s (2012a) study, in which it was found that response inhibition and not trait impulsiveness is 
associated with cue-elicited craving for alcohol. The discrepancy in the findings between the two studies could be due to differences in the populations studied, the type and duration of cue exposure, craving instruments, and differences in the computation of cue-elicited craving. For example, in Papachristou et al.'s (2012a) study, the sample consists of heavy social drinkers, and the alcohol cue exposure lasts only $3 \mathrm{~min}$ and takes place in the laboratory. In the current study, the sample consists of alcohol-dependent inpatients, and the cue exposure is longer and takes place in a real alcohol-related setting.

With regard to variation in determining cue-elicited craving, we have found that unlike trait impulsiveness, response inhibition only predicts absolute cue-elicited craving score in the bar-restaurant and not the increase in cue-elicited craving. These two types of cue-elicited craving, craving change and absolute craving, may have fundamental differences. Regarding craving change for example, the inclusion of a baseline measurement could control for individual differences in responding, expectations, withdrawal craving, and arousal resulting from conflicting drinking goals that could be misinterpreted as craving (Robbins and Ehrman 1992; Sayette et al. 2000; Patterson and Newman 1993; Papachristou et al. 2012b). Furthermore, controlling for craving during neutral cue exposure demonstrates the cue specificity of alcohol craving (Robbins and Ehrman 1992; Tiffany et al. 2000; Carter and Tiffany 1999). The notion of cue specificity is in turn closer to a learning explanation, although a more sophisticated experimental design is required to reach safely this conclusion (Robbins and Ehrman 1992). On the other hand, any of the aforementioned factors could be involved in the absolute cue-elicited craving score in the bar-restaurant and could interact with response inhibition, though this assumption should be supported by future empirical evidence. Therefore, our results are consistent with the broader view that impulsivity consists of multiple dimensions that are uniquely associated with different aspects or indices of alcohol motivation and problems (Christiansen et al. 2012; Lane et al. 2003; Dick et al. 2010; Henges and Marczinski 2012). Alternatively, the relationship between response inhibition and increase in cue-elicited craving could be real but weak, requiring a larger number of participants to be detected statistically.

Although our study contributes to the understanding of the complex relationship between personality and cue reactivity in alcohol-dependence, it is not flawless. It should be noted that alcohol-dependent people are not a homogeneous population (Dom et al. 2006). For example, individual differences in the age of onset of alcohol problems or the presence (or absence) of comorbid antisocial personality disorder or post-traumatic stress disorder could distinguish between more homogeneous subgroups in alcohol dependence. These factors potentially added to the heterogeneity of our study sample and might have affected the extent of cue-elicited craving (Coffey et al. 2010). The limited sample size precludes us to examine this, but in future research it would be interesting to investigate whether the same conclusions can be drawn in more homogeneous groups of alcohol dependent patients (Dom et al. 2006; Verdejo-Garcia et al. 2008). Furthermore, the cue-elicited craving response was reliable but small, which creates doubts about its role in relapse. This could be the result of the reluctance of our participants to admit the full scale of their craving response for reasons related to their patient status and their motivation to remain abstinent (Carter and Tiffany 1999; Wertz and Sayette 2001). Moreover, there were no measures of stress and of severity of alcohol dependence in the present study. However, the exposure to alcohol cues may have been stressful for some patients, and this could have influenced their cue reactivity levels. In the same vein, a higher degree of dependence may reflect a longer learning history or changes in neural systems involved in learning, motivation, and impulsivity; and as a result, it could also have affected cue reactivity levels in the present study (Drummond 2000; Drummond et al. 2000). Additionally, the magnitude of the relationship between trait impulsiveness/response inhibition and cueelicited craving suggests that there is still a great amount of variance in cue-elicited craving that must be explained by other factors. For example, our data displays that age is an important factor in the moderation of cue-elicited craving in alcohol-dependence. Speculating on the nature of this finding, it could be that older patients were more effective at hiding their craving during the cue-exposure or had higher motivation for doing so. Alternatively, it could be that as people grow older, they become less aroused by alcohol-related cues. We suggest that this finding should be the focus of future research because it may have important theoretical and clinical implications for the treatment of elderly alcohol-dependent patients. Finally, the small effect size of the relationship implies that addressing impulsive behavior in order to prevent relapse through a reduction in cue-elicited craving may have limited therapeutic utility.

In summary, our results confirm our hypotheses that both trait impulsiveness and response inhibition influence the intensity of cue-elicited craving in alcohol-dependence. If cue-elicited craving is a motivational index of alcoholseeking and a risk factor for relapse in alcohol dependence (Drummond 2000), then the next step is to examine whether the interaction of impulsivity traits with cue-elicited craving predicts relapse. In that case, both behavioral training and pharmacological treatment for impulsive behavior in tandem with cue exposure with response prevention should be an option in alcohol treatment. Our findings shed some light on these complex relationships and underline the importance of doing further research on the topic. 
Acknowledgment We are grateful to Ingrid Weijnen, director of U-Center, who enabled us to conduct this study. We would also like to thank the U-Center patients for their cooperation during this study and the therapists and staff of the clinic for their invaluable support in recruiting and diagnosing participants.

\section{References}

Anton RF (1999) What is craving? Models and implications for treatment. Alcohol Research and Health 23:165-173

Carter BL, Tiffany ST (1999) Meta-analysis of cue-reactivity in addiction research. Addiction 94:327-340

Christiansen P, Cole JC, Goudie AJ, Field M (2012) Components of behavioral impulsivity and automatic cue approach predict unique variance in hazardous drinking. Psychopharmacology 219:501510

Coffey SF, Schumacher J, Stasiewicz PR, Henslee AM, Baillie LE, Landy N (2010) Craving and physiological reactivity to trauma and alcohol cues in posttraumatic stress disorder and alcohol dependence. Exp Clin Psychopharmacol 18:340-349

Dawe S, Gullo MJ, Loxton NL (2004) Reward drive and rash impulsiveness as dimensions of impulsivity: Implications for substance misuse. Addict Behav 29:1389-1405

Dawe S, Loxton NJ (2004) The role of impulsivity in the development of substance use and eating disorders. Neurosci Biobehav Rev 28:343-351

De Wit H (2008) Impulsivity as a determinant and consequence of drug use: a review of underlying processes. Addict Biol 14:22-31

Dick DM, Smith G, Olausson O, Mitchell SH, Leeman RF, O'Malley SS, Sher K (2010) Understanding the construct of impulsivity and its relationship to alcohol use disorders. Addict Biol 15:217-226

Dom G, Hulstijn W, Sabbe B (2006) Differences in impulsivity and sensation seeking between early- and late-onset alcoholics. Addict Behav 31:298-308

Doran N, McChargue D, Spring B (2008) Effect of impulsivity on cardiovascular and subjective reactivity to smoking cues. Addict Behav 33:167-172

Doran N, Spring B, McChargue D (2007) Effects of impulsivity on craving and behavioral reactivity to smoking cues. Psychopharmacology 194:279-288

Drummond DC (2000) Human models in craving research: What does cue-reactivity have to offer clinical research? Addiction 95:S129 S144

Drummond DC, Litten RX, Lowman C, Hunt WA (2000) Craving research: future directions. Addiction 95:S247-S255

Eagle DM, Bari A, Robbins TW (2008) The neuropsychopharmacology of action inhibition: cross-species translation of the stop-signal and go/no-go tasks. Psychopharmacology 199:439-456

Enticott PG, Ogloff GRP, Bradshaw JL (2006) Associations between laboratory measures of executive control and self-reported impulsivity. Personal Individ Differ 41:285-294

Havermans RC, Mulkens S, Nederkoorn C, Jansen A (2007) The efficacy of cue exposure with response prevention in extinguishing drug and alcohol cue reactivity. Behav Interv 22:121-135

Henges AL, Marczinski CA (2012) Impulsivity and alcohol consumption in young social drinkers. Addict Behav 37:217-220

Kozlowski LT, Pillitteri JL, Sweeney CT, Whitfield KE, Graham JW (1996) Asking questions about urges or craving for cigarettes. Psychol Addict Behav 10:248-260
Lane SD, Cherek DR, Rhoades HM, Pietras CJ, Tcheremissine OV (2003) Relationships among laboratory and psychometric measures of impulsivity: implications in substance abuse and dependence. Addictive Disorders and Their Treatment 2:33-40

Litt MD, Cooney NL, Morse P (2000) Reactivity to alcohol-related stimuli in the laboratory and in the field: predictors of craving in treated alcoholics. Addiction 95:889-900

Logan GD, Schachar RJ, Tannock R (1997) Impulsivity and inhibitory control. Psychol Sci 8:60-64

Nederkoorn C, Baltus M, Guerrieri R, Wiers RW (2009) Heavy drinking is associated with deficient response inhibition in women but not in men. Pharmacol Biochem Behav 93:331-336

Nigg JT, Wong MM, Martel MM, Jester JM, Puttler LI, Glass JM, Adams KM, Fitzgerald HE, Zucker RA (2006) Poor response inhibition as a predictor of problem drinking and illicit drug use in adolescents at risk for alcoholism and other substance use disorders. J Am Acad Child Adolesc Psychiatry 45:468-475

Papachristou H, Nederkoorn C, Corstjens J, Jansen A (2012a) The role of impulsivity and perceived availability on cue-elicited craving for alcohol in social drinkers. Psychopharmacology 224:145-153

Papachristou H, Nederkoorn C, Havermans R, van der Horst M, Jansen A (2012b) Can't stop the craving: The effect of impulsivity on cue-elicited craving for alcohol in heavy and light social drinkers. Psychopharmacology 219:511-518

Patterson CM, Newman JP (1993) Reflectivity and learning from aversive events: toward a psychological mechanism for the syndromes of disinhibition. Psychol Rev 100:716-736

Patton JH, Stanford MS, Barratt ES (1995) Factor structure of the Barratt impulsiveness scale. J Clin Psychol 51:768-774

Robbins SJ, Ehrman RN (1992) Designing studies of drug conditioning in humans. Psychopharmacology 106:143-153

Rohsenow DJ, Niaura RS (1999) Reflections on the state of cuereactivity theories and research. Addiction 94:341-351

Rubio G, Jimenez M, Rodrigo-Jimenez R, Martinez I, Avila C, Ferre F et al (2008) The role of behavioral impulsivity in the development of alcohol dependence: a 4-year follow-up study. Alcohol Clin Exp Res 32:1681-1687

Sayette MA, Shiffman S, Tiffany ST, Niaura RS, Martin CS, Shadel WG (2000) Methodological approaches to craving research: the measurement of drug craving. Addiction 95:S189-S210

Tiffany ST, Carter BL, Singleton EG (2000) Challenges in the manipulation, assessment and interpretation of craving relevant variables. Addiction 95:S177-S187

Verdejo-Garcia A, Lawrence AJ, Clark L (2008) Impulsivity as a vulnerability marker for substance-use disorders: review of findings from high-risk research, problem gamblers, and genetic association studies. Neuroscience and Behavioral Reviews $32: 777-810$

Von Diemen L, Bassani DG, Fuchs SC, Szobot CM, Pechansky F (2008) Impulsivity, age of first alcohol use and substance use disorders among male adolescents: a population based case-control study. Addiction 103:1198-1205

Wertz JM, Sayette MA (2001) A review of the effects of perceived drug use opportunity on self-report urge. Exp Clin Psychopharmacol 9:313

Whiteside SP, Lynam DR (2001) The Five Factor Model and impulsivity: using a structural model of personality to understand impulsivity. Personal Individ Differ 30:669-689

Whiteside SP, Lynam DR (2003) Understanding the role of impulsivity and externalizing psychopathology in alcohol abuse: application of the UPPS impulsive behavior scale. Exp Clin Psychopharmacol $11: 210-217$ 